\title{
Itinerários terapêuticos e novos serviços de saúde mental
}

\section{Therapeutic itinerary and new services of mental health}

\author{
Elisabete Ferreira Mângia ${ }^{1}$, Priscila Mitie Yasutaki ${ }^{2}$
}

\begin{abstract}
MÂNGIA, E. F.; YASUTAKI, P. M. Itinerários terapêuticos e novos serviços de saúde mental. Rev. Ter. Ocup. Univ. São Paulo, v.19, n. 1, p. 61-71, jan./abr. 2008.

RESUMO: Estudos sobre a construção de itinerários terapêuticos trazem importantes contribuições para o planejamento das ações em saúde mental de forma a responder melhor às demandas do novo cenário assistencial. Nessa perspectiva, apresentamos alguns resultados da pesquisa "Itinerários Terapêuticos de usuários do NAPS II do municipio de Santo André", desenvolvida em 2006, que teve como objetivo geral conhecer os itinerários terapêuticos dos usuários e como objetivos secundários: compreender de que forma a enfermidade se incorpora no cotidiano dos sujeitos e em suas redes sociais; identificar as agências de apoio buscadas e a participação dos serviços de saúde mental, e finalmente reconhecer os aspectos que contribuem no processo de tratamento. O trabalho de investigação consistiu em análise documental e pesquisa bibliográfica; elaboração de diário de campo com o acompanhamento das atividades de rotina do serviço e de usuários e realização de entrevistas. Os resultados evidenciaram que os indivíduos encontram diferentes maneiras de lidar com a enfermidade mental e que suas ações são resultado de negociações cotidianas entre o indivíduo afetado e as pessoas de sua rede social. Daí a importância da sinergia entre as ações dos serviços de saúde e aquelas escolhidas pelos sujeitos enfermos no contexto de suas redes sócio familiares.
\end{abstract}

DESCRITORES: Ação intersetorial. Serviços comunitários de saúde mental/utilização. Atividades cotidianas. Entrevista. Centros comunitários de saúde mental/utilização. Serviços de saúde mental/ utilização.

\footnotetext{
1. Profa. Dra. do Curso de Terapia Ocupacional do Departamento de Fisioterapia, Fonoaudiologia e Terapia Ocupacional da FMUSP.

2. Terapeuta Ocupacional graduada pela FMUSP.

Endereço para correspondência: Departamento de Fisioterapia, Fonoaudiologia e Terapia Ocupacional da FMUSP. Rua Cipotânea, 51, Cidade Universitária, São Paulo, SP, CEP: 05360-160.
} 
MÂNGIA, E. F.; YASUTAKI, P. M. Itinerários terapêuticos. Rev. Ter. Ocup. Univ. São Paulo, v.19, n. 1, p. 61-71, jan./abr. 2008.

\section{INTRODUÇÃO}

$\mathrm{O}$ período pós-guerra viu crescer as críticas em relação às instituições asilares e o questionamento dos conceitos de doença e normalidade. Nesse contexto, as instituições psiquiátricas foram alvo de reflexão e projetos de transformação que resultaram em novas propostas de cuidado às pessoas com transtornos mentais ao longo das décadas de 1970-80 (SARACENO, 1999; OMS, 2001).

Dentre essas experiências destacamos a Italiana, pois foi a primeira a propor que o cuidado em saúde mental pudesse prescindir do hospital psiquiátrico, ocorrer em diálogo com as necessidades e contextos de vida dos sujeitos e especialmente, com o aumento de sua participação social e reconhecimento dos seus direitos de cidadania. (ROTELLI et al., 1990). Os novos cenários assistenciais devem aprofundar o conhecimento sobre as ações e contextos que conduzem à melhora dos sujeitos, bem como suas motivações e expectativas em relação ao tratamento (SARACENO, 1999).

No Brasil, o movimento da Reforma Psiquiátrica teve inicio no contexto do processo de redemocratização do país, no âmbito da implantação do Sistema Único de Saúde (SUS). Esse processo operou mudanças profundas nas formas de compreender e cuidar das pessoas com transtornos mentais, expressas claramente nas diretrizes e resultados da atual política nacional de saúde mental.

A partir de iniciativas municipais, têm sido construídas redes de serviços de saúde mental que visam a desinstitucionalização e oferecerem novas respostas às necessidades que emergiram com a ruptura da tutela asilar (AMARANTE, 1998; NICÁCIO, 2003). Essas redes são compostas especialmente, pelos Centros de Atenção Psicossocial (CAPs), Núcleos de Atenção Psicossocial (NAPs), Centros de Convivência, Serviços Residenciais Terapêuticos e equipes de saúde mental na atenção básica. Nelas, os CAPs ocupam um lugar estratégico, pois são concebidos como o centro coordenador das ações de saúde mental (BRASIL, 2004).

As redes de serviços de saúde mental buscam promover a integralidade e humanização do cuidado e colocam como objetivo de suas ações a promoção de saúde e a melhoria da qualidade de vida a partir do desenvolvimento de projetos terapêuticos orientados para a promoção da participação dos sujeitos e integrados aos valores e crenças das comunidadesalvo (MÂNGIA; NICÁCIO, 2001).

Este trabalho buscou conhecer as estratégias utilizadas no enfrentamento dos problemas de saúde mental, por meio da reconstrução dos itinerários terapêuticos de usuários do Núcleo de Atenção Psicossocial II (NAPs II) do município de Santo André.

De acordo com Alves e Souza (1999, p.133), "a idéia de itinerário terapêutico remete a uma cadeia de eventos sucessivos que formam uma unidade (...); designa um conjunto de planos, estratégias e projetos voltados para um objeto pré-concebido: o tratamento da aflição". Conhecer a construção de itinerários terapêuticos propicia o entendimento sobre como ocorre o movimento de identificação dos problemas acarretados pelos transtornos mentais e a busca de soluções que possam estabilizar o cotidiano dos sujeitos e sustentar novas maneiras de organizar suas vidas.

Para alcançar seus objetivos, o estudo coletou narrativas de usuários e suas redes sócio-familiares. O olhar para as experiências individuais buscou elucidar como os indivíduos reorientam suas vidas em situações que implicaram em graves rupturas em suas histórias de vida. Adotou-se também a concepção de que as opções das pessoas, embora singulares, se constroem em interação com a sua rede social e especialmente com o grupo com quem compartilha crenças e práticas (ALVES; SOUZA, 1999). Familiares, cuidadores, amigos e vizinhos, acompanham e vivenciam os processos de ruptura resultantes da enfermidade mental, podendo constituir-se como protagonistas e aliados nas estratégias de cuidado (OMS, 2001).

Considerada a forma mais adequada de acesso à experiência vivida, a narrativa biográfica ocupa espaço privilegiado de encontro entre a vida íntima da pessoa e sua inscrição em uma história social e cultural e se constitui como via de acesso aos significados através dos quais as pessoas constroem sua visão de mundo e as estratégias desenvolvidas diante dos problemas do viver. Consiste em uma forma coerente e adequada de obter informações sobre práticas e saberes de um grupo social em relação à saúde (RABELO, 1999; SILVA; TRENTINI, 2002).

Assim, a investigação desenvolvida pretende trazer contribuições capazes de fortalecerem as estratégias de cuidado em saúde mental e especificamente as práticas desenvolvidas em Terapia Ocupacional.

\section{A investigação}

O estudo monográfico, situado no marco da investigação qualitativa de inspiração etnometodológica (MINAYO, 1993; DESLANDES, 1994) foi realizado no NAPs II do Município de Santo André, que se apresenta enquanto um serviço substitutivo e territorial, de tipo CAPS III, com funcionamento, 24 horas (BRASIL, 2004). Ocorreu no contexto do desenvolvimento da pesquisa "Estudo 
Colaborativo sobre a experiência da rede de serviços em saúde mental do municipio de Santo André - SP: caracterizando os serviços, conhecendo resultados e desenvolvendo um experimento sobre a ativação de rede social", aprovada pelo Comitê de Ética do Hospital das Clínicas da Faculdade de Medicina da Universidade de São Paulo.

O trabalho de investigação consistiu em análise documental e pesquisa bibliográfica; elaboração de diário de campo com o acompanhamento das atividades de rotina do serviço e de usuários e realização de entrevistas. Os dados foram coletados no período de março de 2006 a janeiro de 2007.

Foram colhidas narrativas de 4 usuários e de pessoas de suas redes sociais. Todas as entrevistas foram antecedidas de consentimento livre e esclarecido e o trabalho precedido de autorização institucional. As entrevistas ocorreram em dois momentos: primeiramente foi colocada uma questão geral a respeito da história da enfermidade relacionada ao itinerário terapêutico, deixando que o depoente falasse livremente sobre o tema e, posteriormente, foram colocadas questões mais específicas em relação ao momento atual do usuário no serviço. Os dados foram analisados de acordo com o objetivo central do trabalho que buscou conhecer os itinerários terapêuticos dos usuários e ainda pretendeu: compreender de que forma a enfermidade se incorpora no cotidiano dos sujeitos e em suas redes sociais; identificar as agências de apoio buscadas e a participação dos serviços de saúde mental, e finalmente reconhecer os aspectos que contribuem no processo de tratamento.

A inserção no serviço de saúde mental possibilitou a observação do cotidiano dos usuários e criou um campo de interação que permitiu a compreensão de seus itinerários terapêuticos, relatados em pequenas histórias ao longo desse percurso.

Foram entrevistados 4 usuários, dois homens e duas mulheres, entre 25 e 50 anos. Todos estavam em tratamento há pelo menos 6 meses, em regime de acompanhamento intensivo e utilização de períodos de hospitalidade noturna, sendo caracterizados como pacientes graves. Para esses usuários foram adotados os nomes fictícios de Abel, Bia, Ciça e Robson.

\section{Os participantes e seus itinerários terapêuticos}

\section{Abel}

Nascido em março de 1959, é o terceiro filho de uma prole de cinco, morava com uma irmã, deficiente auditiva e o irmão mais novo. Abel teve na música a sua principal ocupação, fazendo apresentações e ministrando aulas de violão. Perdeu o pai na adolescência e cuidou da mãe acamada, que faleceu no dia de seu aniversário, em 1987, dois anos antes de sua primeira crise. Correlacionava a enfermidade com vários aspectos de sua vida: a falta de suporte e estrutura emocional para cuidar da mãe; o uso de álcool e drogas por muito tempo; além de causas espirituais.

Iniciou o tratamento no NAPs em janeiro de 1989, após um episódio psicótico ocorrido quando se apresentava em um restaurante no litoral de São Paulo. Relata que passou a ter alucinações, o que ocasionava episódios de auto e hetero agressividade e ideações suicidas. Viveu períodos de depressão. Perdeu muitos contatos profissionais, restando apenas um amigo que se manteve próximo. No período da pesquisa, convivia bem com os sintomas que pareciam não ocasionar rupturas no curso de sua vida.

Como conseqüência da enfermidade identificava a falta de memória e a diminuição da coordenação motora, com grande prejuízo para se desempenho como músico. No final de 2006, frequentava o NAPs apenas para consultas médicas, busca de medicação e auxílio para trabalhar. Além do serviço de saúde mental, procurou auxílio em casas espíritas e igrejas evangélicas. Mantinha em relação aos irmãos uma posição ambígua, ora os considerava como fonte de auxílio e ora como razão de recaídas.

\section{Bia}

Nasceu em dezembro de 1963 e sua mãe faleceu no parto. Morou com o pai até os 6 anos de idade, quando foi entregue a ex-patroa da mãe, com quem morou até os 16 anos. Nesta época teve um filho que foi tomado pela mãe de criação.

Chegou ao NAPs em julho de 1999, acompanhada por uma amiga que desempenhava papel importante em sua vida. Passou por inúmeras internações psiquiátricas. Na época da última, em 1999, trabalhava em um salão de cabeleireiro e em um bar e fazia uso abusivo de álcool. Acreditava que sua enfermidade teve como causa um acidente de carro acontecido em 1992, quando teria batido a cabeça e ficado "abobada".

Nas crises, ficava muito agitada, "acelerada e agressiva, e arranjava confusão" com outras pessoas. Quando iniciou o tratamento no NAPs, havia perdido a guarda de sua filha. No final de 2006, com sua melhora e intervenções do serviço junto ao Conselho Tutelar, recuperou a criança. Nos momentos de crise contou com ex-companheiros, uma amiga mais próxima e os antigos patrões. Para ela os profissionais do NAPs constituíram também referências importantes. 
MÂNGIA, E. F.; YASUTAKI, P. M. Itinerários terapêuticos. Rev. Ter. Ocup. Univ. São Paulo, v.19, n. 1, p. 61-71, jan./abr. 2008.

\section{Ciça}

Nascida em janeiro de 1961, iniciou o tratamento no NAPs em fevereiro de 2000, após longa história de internações, iniciadas aos 11 anos de idade. Relatos informam que ela costumava fugir de casa e deitar-se na rua e por isso era levada ao hospital. Atribui a enfermidade a várias mortes na família; a da mãe, quando tinha 16 anos; a da irmã, cujo atropelamento presenciou; e ao cuidado dispensado ao pai, ao longo de dez anos, até sua morte. Compreende também, como causa de sofrimento, a sua precária condição de moradia. Sua saúde física sempre foi frágil tendo demandado inúmeros tratamentos clínicos.

Chegou ao NAPs encaminhada por uma UBS e enfrentou dificuldade inicial em aderir ao tratamento, pois queria continuar trabalhando. Ciça viveu crises de pânico e períodos depressivos nos quais não conseguia cuidar de si e das atividades domésticas. Foi alvo de tratamento intensivo diurno com utilização de hospitalidade noturna. No início de 2007 recorria ao serviço apenas para pegar medicamentos e em momentos de mais dificuldade em sua vida pessoal. Para ela, os profissionais do serviço se tornaram uma importante referência ao fornecerem escuta e atendimento às suas necessidades.

\section{Robson}

Nasceu em outubro de 1980 na Bahia. Relata que a primeira crise ocorreu ao saber que seu filho recém nascido necessitava de cirurgia cardíaca. Viveu muitas internações até chegar ao NAPS em 2003, onde passou a ser atendido em regime intensivo com utilização de hospitalidade noturna. Encontrou apoio na família que o levou também a buscar igrejas e aconselhamento espiritual. Durante suas crises, Robson se tornava agressivo, muito diferente de seu comportamento habitual, calmo e sociável.

Veio para São Paulo ao encontrar trabalho na mesma empresa onde trabalhava seu irmão, mas foi considerado inadaptado, "lerdo" e "sonolento". Depois disto, nunca mais trabalhou. Sua rotina se restringia á vida doméstica e a frequência ao NAPS.

\section{Enfermidade, cotidiano e rede social}

A enfermidade mental constitui uma situação problema que demanda rearranjos no cotidiano dos sujeitos e de sua rede social. Sua compreensão e formas de enfrentamento são construções resultantes da interação do individuo com seu contexto, de forma que este tem participação ativa desde a identificação do problema até a orientação e avaliação de escolhas terapêuticas. Considerando que as trajetórias estudadas são de usuários graves, com histórias de múltiplas internações identifica-se nesse grupo graves rupturas nos percursos de vida caracterizadas pelo abandono das atividades cotidianas, profissionais, domésticas, papéis familiares e vínculos afetivos.

Suas narrativas enfatizaram a problemática dos sintomas e sofrimentos relacionados à enfermidade: depressão, pânico, desespero, agressividade. Como conseqüência, muitos optaram pelo isolamento doméstico e vivenciaram a perda de sentido da vida.

Já as narrativas de membros da rede social enfatizam as conseqüências da enfermidade no desempenho das atividades rotineiras, tanto referentes às atividades diárias, quanto ao desempenho de papéis sociais. Em todos os casos investigados, a situação de enfermidade mental implicou, total ou parcialmente, na expropriação de suas identidades e na redução de seus papéis sociais ao papel de doentes. $\mathrm{O}$ trabalho, as tarefas domésticas e inclusive o auto-cuidado deixam de fazer parte das atividades rotineiras das pessoas e se tornam encargos da rede social.

Abel vivenciou longo processo até decidir parar de realizar apresentações musicais, restringindo seu cotidiano à rotina do serviço de saúde. De maneira semelhante, Bia parou de trabalhar em razão das crises e internações. Três das quatro pessoas investigadas possuíam filhos e relataram com muito sofrimento as experiências de restrições em seus papéis familiares. Bia perdeu a guarda da filha recém nascida por quase um ano, contou com a disponibilidade de uma amiga para cuidar da criança enquanto estivesse em tratamento, mas seu companheiro, não concordou e o bebê foi retirado de casa pela Vara da Infância e levado para um abrigo. Robson foi privado de ficar com o filho durante o período de tratamento, mas a separação foi mais amena pois seus irmãos se encarregaram de cuidar da criança.

Diferentemente de Bia e Robson, Ciça parecia não se importar com o cuidado e julgava que sua presença como mãe era indiferente. Sua trajetória fazia supor que a experiência de institucionalização, pela qual passou, a subordinaram ao papel de incapacitada, gerando dificuldades para o estabelecimento de outro tipo de relação que não aquela permeada pela doença. Assim, tendia a se relacionar com todos por solicitações de cuidado.

"eu queria a minha mãe me ajudando, e minha mãe não podia me ajudar, ela queria carinho... só que, eu que queria carinho, lógico, eu! (...) Quando eu ganhei o Lucas, ela se $f e z$ de bebê, .... Então eu não aceitava. Prá mim ela tinha que ajudar, ajudar eu a cuidar" (Mirian, filha de Ciça).

Rotelli (1999), assinala que, em muitos casos, a presença da enfermidade mental implica na expropriação da identidade e na produção de dependência e cronicidade, 
MÂNGIA, E. F.; YASUTAKI, P. M. Itinerários terapêuticos. Rev. Ter. Ocup. Univ. São Paulo, v.19, n. 1, p. 61-71, jan./abr. 2008.

pois a terapia proposta pelas instituições asilares se constitui como instrumento de controle, dominação e exclusão social. Interessa-nos perceber a dimensão do controle solicitado diante de situações que desorganizam os sujeitos e que levam os familiares e a rede social a buscarem respaldo nas instituições asilares, seja por não saberem o que fazer diante da situação de crise, seja pela imprevisibilidade que ela pode representar. A rede social próxima é reconhecida como a primeira e, às vezes, a principal referência de apoio diante da enfermidade. Nas situações de crise recai sobre esta a tomada de decisões sobre o sujeito afetado.

"o meu patrão, foi ele que fez tudo isso prá mim. Que resgatava prá trabalhar, que internava. E dai da ultima vez ele falou prá Déia: 'pode deixar que agora ela tá aqui e eu cuido dela'. E ele que levou. Ele foi muito bom” (Bia).

"Essa amiga minha, Mirian, foi quem me levou por muito tempo, (...) no hospital, lá nesse hospital ai onde eu to fazendo tratamento, me levava e me buscava, né...Qualquer coisinha eu ligo na casa dela...". (Ciça).

Meu irmão que levava eu... Sempre quando eu caia na crise, meus irmãos me internavam... Sempre as pessoas da família que me ajudam, meus parentes... (Robson).

Nota-se que a rede social próxima dos sujeitos estudados não corresponde necessariamente aos familiares: Bia construiu um forte laço de amizade com a dona da pensão onde morou que passou a acompanhá-la desde a primeira crise. Ciça não encontrou respaldo nas irmãs, pois elas não acreditavam em sua enfermidade, mas obteve muito apoio das vizinhas. Em sua história se percebe o processo de construção social da enfermidade e como os sujeitos justificam suas atitudes a partir do entendimento que desenvolvem e compartilham sobre a enfermidade mental. As narrativas mostraram que a enfermidade era ignorada pelos familiares até a aproximação das vizinhas que traziam as mensagens do serviço de saúde.

"A minha mãe deixava de falar coisa comigo, (...) prá falar com a Maria. A vida toda foi falando com a Maria. Que a minha tia, ninguém ligou de lá de casa (...) antes eu não aceitava, todo mundo falava. Não aceitava, porque as vezes ela tomava remédio e dormia na rua (...). Prá mim era graça dela (...) Ai eu fui conhecendo o povo do hospital (refere-se ao NAPs como hospital). A Maria foi conversando comigo, ai eu fui conhecendo, fiquei numa consciência, ela tinha depressão, mas antes eu não aceitava,. Prá mim era normal, era graça, ela gostava de fazer graça". (Mari, filha de Ciça).

Os irmãos de Robson também desconfiaram de sua doença, mas buscaram orientações no NAPs e passaram a desenvolver outra compreensão sobre a situação. Abel e Robson foram levados pelos respectivos patrões a serviços de saúde no primeiro sinal de crise, e Bia foi levada pelo marido ao hospital psiquiátrico.

Para todo o grupo, o ingresso no serviço de saúde implicou em ruptura na vida cotidiana e perda de papéis sociais. Diante dessas rupturas outras pessoas foram chamadas a assumirem os papéis antes exercidos pela pessoa enferma. No entanto, as pessoas da rede social, após acolherem por um período a solicitação de auxilio, logo passam a sentirem-se sobrecarregadas e demonstram dificuldade em se manterem nessa posição. Frequentemente se percebe a existência de dependência extrema a uma única pessoa, mesmo quando os técnicos de saúde mental se constituem como referência. Abel foi o único a ter mais de uma pessoa como referência extra-institucional. No entanto seu irmão mais novo sentia-se sobrecarregado em relação aos três irmãos que não trabalhavam. Déia também reclamava da sobrecarga nos cuidados com Bia.

“...às vezes eu me sinto até assim, sabe? Com sentimento de culpa por não poder colocar a mão na cabeça dele e resolver os problemas (...) O que eu não quero é me tornar o pai dos meus irmãos, que são muito mais velhos que eu. Eu sinto assim que tá havendo um abuso. Você já ouviu a história do chupim? Do pássaro? Me falaram que o chupim vem e bota o ovo junto com os ovos do tico-tico. Ai ele vai crescendo, vai ficando grande, até que a passarinha, mãe, não consegue mais lidar e acaba morrendo porque tudo o que pega ele vai consumindo. Então não consegue dar conta do pássaro enorme. E o que acontece comigo é assim". (José, irmão de Abel).

“Ah,(...) ela não dá sossego... É como se fosse um familiar, ... fica agitada... Incomoda... me atrapalha a vida.. Eu deixo de fazer alguma coisa prá dar atenção prá ela. Às vezes quando ela ta internada, visitá-la, né, acompanhar um pouco ela... Porque ela também, ela liga direto, ela me procura, né... (Déia).

As pessoas da rede social relataram também perdas e prejuízos que vivenciaram devido à enfermidade de uma pessoa próxima. A filha de Ciça, falou da dificuldade vivenciada com a chegada de seu filho devido à enfermidade de sua mãe. A mãe comportou-se como uma filha que concorria com o bebê recém chegado. Os irmãos de Robson e de Abel relataram situações de sobrecarga e faltas no trabalho.

Pudemos verificar que a rede social não atua na vida da pessoa com enfermidade mental apenas no sentido positivo. Há situações de conflito, muitas vezes o estigma da doença mental provoca atitudes de zombaria e afastamento por parte 
MÂNGIA, E. F.; YASUTAKI, P. M. Itinerários terapêuticos. Rev. Ter. Ocup. Univ. São Paulo, v.19, n. 1, p. 61-71, jan./abr. 2008.

de pessoas próximas. Em tais situações, membros da rede sócio familiar são convocados a intervirem.

\begin{abstract}
"Às vezes até criança, o adolescente que não entende a doença, muitas vezes eles dizem: a Ciça é doida! Sabe essas brincadeiras idiotas? Isso atrapalha. (...) acho que isso irrita muito a pessoa porque... Até a gente. Você tem que estar muito assim equilibrado prá não ligar, né? Ai eu sempre falo, quando eles falar (...) não liga (...) atravessa a rua e vai prá outro lado (...) As pessoas não tem compreensão. Mas isso, faz parte do mundo. Parece que cada vez as pessoas estão mais intolerantes". (Mirian, amiga de Ciça).
\end{abstract}

$\mathrm{O}$ conceito de enfermidade mental se relaciona à identidade do individuo como o resultado de um campo de relações que este estabelece. A partir da percepção da enfermidade, uma série de relações são interrompidas e, com isso, a identidade da pessoa parece se dissolver, se perder:

“um 'eu' (self) responsável define-se por sua inserção em uma teia de relacionamentos, implicando obrigações diferenciais para com outro. Um sujeito enfraquecido ou diminuído é, ao contrário, um ser deslocado" (RABELO el al., 1999, p. 71).

Em todos os casos, a chegada ao serviço de saúde mental determinou a maior ruptura nas atividades cotidianas. Isso ocorre pela tendência dos serviços em totalizarem a vida da pessoa, seja por meio de internações, seja pelos longos períodos em tratamento intensivo nos serviços abertos. Ao privarem a pessoa de exercer seus papéis sociais, que conferem sentido à vida por conectá-la ao mundo, os serviços acabem por produzir um efeito oposto ao esperado pelo processo de promoção da saúde. Os longos períodos de tratamento, reforçados pelo uso indiscriminado de fármacos, utilizados no controle dos sintomas, parecem extinguir a vitalidade dos sujeitos. Se a enfermidade já é vivida como a perda de um lugar, os serviços de saúde, muitas vezes, intensificam o desenraizamento do indivíduo.

Neste processo, a rede social do indivíduo pode exercer um papel fundamental, que tanto pode protegê-lo, cuidando de resguardar seu lugar social (auxiliando no cuidado aos filhos, intermediando as relações conflitantes, provendo-lhe materialmente, afetivamente etc), quanto pode reforçar o lugar de exclusão, quando há perda de identidade ou invalidação do indivíduo diante da superproteção ou abandono das pessoas próximas.

A rede social participa ativamente do processo de reconhecimento da enfermidade, da criação de estratégias cotidianas, escolha e avaliação dos auxílios possíveis, que ocorrem a partir de negociações e em um campo de significados compartilhados. No entanto, foi possível observar que as relações entre o indivíduo enfermo e sua rede social estão permeadas por ambigüidades e constantes questionamentos a respeito da posição que ocupam.

Em todos os casos, o cuidado com a pessoa enferma recai com muita força sobre uma pessoa principal da rede social, que fica solitária e sobrecarregada neste cuidado, além de gerar uma dependência às vezes imobilizadora. Imobilizadora pois, ao depender muito de poucas relações, a pessoa restringe a possibilidade de desenvolver maior autonomia. Ao refletir sobre a relação totalizadora que se estabelece entre pacientes e instituições asilares, Kinoshita defende que a pessoa será mais autônoma quanto mais puder depender de uma variedade de recursos. (KINOSHITA, 2001). Este deve ser um norteador das práticas dos serviços de saúde mental que se propõem a reabilitar as pessoas de maneira a incluí-la socialmente.

\section{A busca de apoio}

O grupo estudado viveu trajetórias semelhantes na busca de apoio. Familiares, vizinhos e colegas de trabalho são os grupos primeiramente acessados e quando mobilizados contribuem para criar estratégias para lidar com o sofrimento. Notam-se diferentes atitudes em relação à enfermidade mental. Algumas pessoas suportam a situação por maior período, antes de buscarem algum tipo de auxílio, enquanto outras o fazem ao menor sinal de diferença no comportamento da pessoa enferma. Todos passaram por períodos de internação psiquiátrica antes de chegarem ao NAPS. As narrativas descrevem a percepção negativa sobre a hospitalização psiquiátrica, enfatizando abandono, formas de relação violentas com profissionais e entre as pessoas lá internadas, condições colocadas às vezes como as causadoras dos principais sofrimentos atuais das pessoas investigadas:

"Lá eu ficava trancado, lá no Escania. Não tinha nada pra fazer e eu ficava trancado, preso (...) A gente não tomava café de manhã. Passava da hora, não chamavam. Ai eu tomava, só almoçava, duas horas, uma hora, ou doze hora, tomava remédio duas hora, ai ficava preso lá, não saia pra canto nenhum..." (Robson).

Após conhecerem o NAPs, Bia, Ciça e Abel nunca mais foram internados em instituições fechadas, mas recorreram da hospitalidade noturna em algum período. A existência e acesso a este procedimento permitiram a sustentabilidade de um cotidiano longe das instituições asilares nos períodos mais difíceis. O NAPs, foi bem avaliado pelas pessoas, que reconheceram a diferença na relação estabelecida pelos profissionais no que diz respeito ao cuidado, à escuta e à disponibilidade, daquelas estabelecidas por profissionais de instituições asilares. Além disso, a atenção às várias esferas 
da vida da pessoa (material, afetiva, social) faz alguns usuários o qualificarem como um serviço completo.

\begin{abstract}
"Aqui as pessoas incentiva mais a gente, dá mais atenção na gente (...) se não lembrei de tomar remédio naquele dia, eles vem e chama atenção pra eu tomar remédio... e sempre, assim, é melhor aqui. Porque aqui eu vou embora, não fico preso o dia todo, vou embora pra casa. Venho de manhã e vou volto à tarde. Se quiser, vou, tomo remédio aqui e volto pra casa (...). (Robson).
\end{abstract}

Apesar da tendência verificada em desqualificar as instituições asilares, estas ainda são vistas como necessárias em alguns casos.

"As crises são sempre caóticas mesmo. A única solução que nós vemos, eu sei que é difícil ficar naquele lugar, mas a única solução é a internação. Porque ele não conhece nada aqui onde ele mora, ele saiu sozinho lá prá um lugar pegar onibus, mas ele nem sabe que ônibus é, e muitas vezes ele pega o filho dele e sai e nós não confia. Que nem quando ele tava na crise, ele pegou o filho dele, e saiu, nós não confia. Ai devido a isso aí, nós fica com essa preocupação”. (Gerson, irmão de Robson).

Embora reconhecido como um serviço que se preocupa e toma providências em relação às diversas esferas da vida de seus usuários (social, material, afetiva), se observou algumas críticas ao seu papel. A principal delas consiste em avaliar que o serviço parece produzir a dependência excessiva dos usuários, que sentem muita dificuldade em retomar a vida fora da instituição depois da experiência de ter a vida restrita às relações e rotinas do NAPs. Além disso, outra queixa dirigida ao NAPs se relaciona à privação implicada no tratamento.

Nessa direção é importante ressaltar importância das instituições que se ocupam em promover apoio social e busca de alternativas de trabalho para os usuários, como é o caso da Organização Social de Volta para Casa e da Casa Amarela, em Santo André. Elas compõem a rede de serviços de saúde mental do município, assumem a orientação sobre benefícios e oferecem diversos cursos de capacitação profissional. São também lugares de relações afetivas importantes. Essa rede consegue oferecer uma trajetória de cuidados que ao responder à complexidade das necessidades dos usuários, prescinde da internação.

"Quando eu saia do hospital psiquiátrico, meu patrão resgatava eu de novo prá trabalhar, porque eu trabalhava muito bem. Ai, depois, quem me internou da ultima vez foi a Denise, que me levou a chegar no NAPs, entendeu? Levou eu prá Casa Amarela (...) Eu passei dois anos lá, na casa amarela. Lá é diferente (...) E eles pegam sua carteirinha e você vai trabalhar fora e eles tiram seus documentos. Igual vocês faz, vocês faz lá no NAPS, na OS, tiram seus documentos e põem você na rua de novo prá trabalhar, sem medo de nada." (Bia).

Finalmente importa destacar o papel importante das instituições religiosas na composição dos itinerários terapêuticos dos usuários. A trajetória de Abel é exemplar, pois ele chegou a abandonar o tratamento no NAPs por acreditar que seu problema era de natureza espiritual. Passou a frequentar seitas espíritas e igrejas evangélicas, suspendeu o uso da medicação o que, talvez, tenha desencadeado nova crise que o levou de volta ao serviço de saúde mental. Nesse processo, continuou a freqüentar a igreja, que parece conferir sentido à sua existência, além de tê-lo ajudado a interromper o uso de drogas.

"Acredito que a igreja me ajudou bastante (...)Por isso que eu me apego à igreja. Porque a igreja te faz ficar mais (...) sabendo o que você é... Acho que a igreja me ajudou mais no sentido amplo. Não que tenha feito milagres nem nada. É que ... é... qualidade de vida, né... coisa mais de saber o que fazer, saber onde andar, tal." (Abel).

Para Robson, sua crença em Deus parece conferir força e suporte para que ele e sua família sigam assumindo o cuidado necessário na experiência da enfermidade.

“muitas vezes você fica triste, abatido, mas graças a Deus que Deus vai sempre dando graça, (...), nós vai levantando nosso ego, nossa auto estima, porque tudo o que ele não pode fazer, nós temos a nossa saúde, e vamos fazer por ele pra tentar ajudar ele no que der"(Gerson, irmão de Robson).

Foi possível perceber que a busca de cuidado não é orientada, à priori, por um modelo específico, mas ocorre de acordo com as respostas reconhecidas socialmente. Evidencia isto o fato dos usuários não terem se recusado às sucessivas internações, por mais que percebessem a violência nas relações estabelecidas nas instituições. Entende-se isso pelo lugar de legitimidade conferido ao hospital no cuidado do transtorno mental. São as sucessivas experimentações práticas que constituem a base para um conhecimento e avaliação mais organizada sobre as decisões e escolhas presentes nos itinerários terapêuticos (ALVES et al., 1999).

Assim, a possibilidade dos sujeitos escolherem a forma de tratamento preferencial ocorre após a experimentação de opções oferecidas pelo seu contexto social. No geral, os usuários chegaram ao NAPs por encaminhamento de outros serviços de saúde ou por indicação de membros de sua rede social e sem possuírem uma imagem ou expectativa estruturada sobre a oferta do serviço.

Observou-se também, pouca apropriação da idéia da saúde como um direito do cidadão, que se constitui como 
MÂNGIA, E. F.; YASUTAKI, P. M. Itinerários terapêuticos. Rev. Ter. Ocup. Univ. São Paulo, v.19, n. 1, p. 61-71, jan./abr. 2008.

um aspecto da constituição brasileira e é diretriz central do Sistema Único de Saúde. Há também pouca informação sobre as novas diretrizes para o tratamento em saúde mental e cabe aos serviços a sensibilização para tais aspectos, fundamentais para a mudança das relações entre usuários e serviços de saúde mental (COHN et al., 1991).

Num contexto plural, os usuários parecem não fazer distinções entre os diversos tipos de cuidado acessados, o que acaba por definir trajetórias heterogêneas e não lineares. Como exemplo: Abel chegou a interrompeu o tratamento no NAPs por considerar que seu problema era espiritual. Buscou auxílio em igrejas pentecostais e seitas espíritas, que adotam compreensões do mundo muito distintas, e que costumam estabelecer uma relação até conflitante entre si.

Nenhum dos entrevistados pareceu perceber que os tratamentos propostos nas instituições asilares e nos NAPs adotam estratégias e orientações muito distintas No caso de Robson, cada uma dessas instituições foi acessada de acordo com a característica da crise, como se fossem complementares: o NAPs para um auxilio mais brando e o hospital para situações fora do controle. Vê-se que, em geral, as pessoas buscam auxilio sem conhecer a lógica interna que adotam (ALVES, 1993) e é a experiência vivida que irá definir a avaliação dos usuários sobre as diversas alternativas que encontram em suas trajetórias.

\section{Contexto de vida, história da enfermidade e formas de tratamento}

Ao refletir sobre a relação entre diagnósticos psiquiátricos e tratamentos, Saraceno conclui que as informações que melhor contribuem para a orientação das intervenções estão mais conectadas à vida das pessoas do que ao diagnóstico que lhes é atribuído (SARACENO, 1999). Através das narrativas foi possível identificar alguns desses aspectos que interferem na história da enfermidade.

A aproximação com as trajetórias de vida dos entrevistados evidencia que as redes sociais têm participação ativa na definição, administração e criação de estratégias de convívio com a enfermidade. No entanto, embora dêem suporte ao individuo, as reações dos componentes das redes diante da enfermidade são heterogêneas, repletas de ambigüidades e podem, ao mesmo tempo, trazer suporte e contribuições ou desgaste e prejuízos para os sujeitos, de forma que os serviços de saúde podem desempenhar um papel importante na mediação de conflitos e intervenções que busquem proteger os sujeitos dos efeitos negativos de tais redes. A trajetória de Abel é exemplar, pois embora contando com o apoio dos irmãos, os conflitos familiares o levaram a uma tentativa de suicídio.

Tais considerações também são pertinentes em relação ao uso da medicação. As pessoas envolvidas no cuidado defendem que as orientações médicas devem ser seguidas com disciplina, sob o risco de recaídas. No entanto, raramente há uma forte responsabilização em relação ao tratamento medicamentoso, por parte dos componentes das redes sócio familiares.

"ele toma medicamento ai melhora. Quando toma medicamento... Ai, se pára de tomar medicamento, piora " (José, irmão de Abel).

"é que quando ela ta tomando remédio, ela tem condição de ficar bem. Ela parou de tomar remédio, logo volta a crise, ela tem condições, tomando o remédio. Eu acho que ela tem que tomar remédio pelo resto da vida (...)Mas se ela tomasse o remédio direitinho, ela tinha condição de criar a criança direitinho (...)" (Deia).

A associação entre a administração da medicação e a melhora também deve ser questionada. Verifica-se que, para a maior parte dos casos, o efeito esperado da medicação é conter a ansiedade, a produção psicótica, a agressividade, enfim, amenizar os sintomas mais angustiantes e insuportáveis à rede social do indivíduo com enfermidade mental, produzindo um estado de sedação. No entanto, o que percebemos nas narrativas é que, ao produzir este estado de calma, a medicação elimina a vitalidade do indivíduo, que fica sonolento e lentificado, como se perdesse sua condição de pessoa. Por mais que a família se sinta aliviada com a ausência dos comportamentos desviantes, a medicação não resulta necessariamente na melhora, mas produz efeitos iatrogênicos, substituindo o sofrimento, antes focado na presença da enfermidade, pela anulação da subjetividade do indivíduo.

"eu queria fazer ele não ficar dependendo tanto dos remédios porque a pessoa fica com aparência muito ruim, semblante caído. A pessoa fica meio esquisita mesmo quando toma esses remédios... (...) eu percebi que todas as pessoas que tomam esses remédios ficam assim... chegam a babar, né." (José, irmão de Abel).

"Eu espero que a minha mãe também não fique a vida toda tomando um monte de remédio... Eu não agüento ver ela tomando um monte de remédio, assim, eu acho que devia diminuir... Porque é um monte de remédio e deixa ela dopada. (...) Então eu acho que tinha que ser menos remédio e mais ajuda, assim da família, dos médico, de tudo..." (Mari, filha de Ciça).

Robson mostra sua avaliação sobre o uso da medicação ao reconhecer que fica mais orientado com seu uso, mas 
MÂNGIA, E. F.; YASUTAKI, P. M. Itinerários terapêuticos. Rev. Ter. Ocup. Univ. São Paulo, v.19, n. 1, p. 61-71, jan./abr. 2008.

devido à grande quantidade de efeitos colaterais, sente-se incapaz de comprometer-se com projetos futuros e de voltar a ser uma pessoa independente e autônoma.

\begin{abstract}
"Ah, logo depois que tomei essa injeção que to tomando agora, aqui, to sentindo muitas dores no corpo (...). Eu tomo cinco ampolas todo mês, (...) to melhorando... Sei o que eu faço, sei o que eu falo, sei o que tenho que fazer, onde tenho que fazer. Apesar de tudo (...) eu tava com uma namorada aqui em São Paulo, (...), mas eu não quis ficar com ela porque eu tava sem trabalho e tava tomando esse medicamento, ai eu falei: 'Não consigo trabalhar pra te sustentar'(...) Ai eu canso muito... eu chego em casa e meu filho quer sair prá brincar um pouco, eu saio com ele, mas saio com cansaço, saio com sono, e cansaço, sinto muito cansaço no corpo.... Então, eu to um pouco meio abatido porque não sei se é o remédio que é forte demais. Você nunca sabe, sabe, fico muito abatido. Parece que minhas força foi tudo embora... tomando injeção, tomando remédio..." (Robson).
\end{abstract}

A fé é considerada um aspecto importante na trajetória de algumas pessoas entrevistadas. Nenhuma delas relatou especificamente as expectativas que depositavam na busca de auxilio em agencias religiosas e nem como imaginavam alcançá-las, mas deram ênfase ao ato de fé como importante para conferir força, suporte e perseverança no tratamento.

Todas as pessoas entrevistadas comentaram sobre a importância da escuta, da atenção e do afeto investidos no cuidado à saúde no processo de melhora:

"Lá no NAPs eu me sinto aliviada. Porque a gente acha o amor, o carinho, principalmente da referência da gente, da minha médica, tem os médico que a gente pode chegar nele quando ta sentindo mal, então..." (Ciça).

"Aqui (NAPs II) as pessoas incentiva mais a gente, dá mais atenção na gente. Não deixa a gente... Se passar, não tomar remédio, se não lembrei de tomar remédio naquele dia, eles vem e chama atenção pra eu tomar remédio... e sempre, assim, é melhor aqui. Porque aqui eu vou embora, não fico preso o dia todo, vou embora pra casa. Venho de manhã e vou volta à tarde. Se quiser, vou, tomo remédio aqui e volto pra casa, se quiser, volto pra buscar remédio e volto de novo pra casa." (Robson).

Algumas narrativas demonstram o reconhecimento sobre a importância do aumento do campo relacional nas vidas que se tornaram reduzidas à doença. A possibilidade de realizar trocas e relações significativas com o meio social é colocada como a prova de melhora. Saraceno concorda com esse ponto de vista ao defender que a reabilitação constitui "um conjunto de estratégias orientadas a aumentar as possibilidades de troca de recursos e afetos" (SARACENO, 1999, p. 112).
O trabalho é um importante eixo que possibilita reprodução da vida. Considerando suas funções econômicas, sociais e psicológicas: trata-se de um "espaço de produção de sentido, valores subjetivos e de troca" (SARACENO, 1999, p. 140). O trabalho permite a construção de um lugar de existência e participação no mundo na medida em que confere aos indivíduos a possibilidade de trocar valores (materiais e simbólicos). Indica, assim, uma determinada forma de funcionamento social e de capacidade de adaptação do indivíduo. Pudemos observar nas narrativas a importância dada à possibilidade de trabalhar, sendo colocada como um indicativo de melhora, da mesma forma que um dos primeiros sinais que identificam a enfermidade é a ruptura com o trabalho.

Percebemos que os aspectos que têm maior peso como indicativos de melhora são aqueles que rompem com a cristalização do indivíduo no papel de enfermo, e criam condições que possibilitam o exercício de sua subjetividade (ROTELLI, 1999).

\section{CONSIDERAÇÕES FINAIS}

A investigação sobre os itinerários terapêuticos evidenciou que os indivíduos encontram diferentes maneiras de lidar com a enfermidade mental e que suas ações são resultado de negociações cotidianas entre o indivíduo afetado pela enfermidade e as pessoas de sua rede social. Essas ações não são dirigidas segundo uma lógica pré-concebida, mas as escolhas são orientadas segundo necessidades práticas. Para responder às demandas que surgem com a enfermidade mental concorrem diversos tipos de explicações e conhecimentos que se modificam continuamente, o que permite que sejam desenhados itinerários terapêuticos que se utilizam, ao mesmo tempo, de várias formas de cuidado, às vezes até contraditórias entre si (ALVES; SOUZA, 1999).

Investigar os itinerários terapêuticos suas ambigüidades e contradições contribui para a reflexão sobre as ações em saúde mental desenvolvidas pelos novos serviços substitutivos. Possibilita reconhecer a importância do conhecimento sobre a trajetória da vida do usuário, como elemento fundamental na reconstrução do percurso social e institucional da pessoa abalada pela enfermidade.

A sinergia entre as ações propostas pelos serviços e aquelas possibilitadas pelas redes sócio familiares viabiliza a construção de projetos terapêuticos factíveis, dotados de sentido para os sujeitos e capazes de romperem com o círculo vicioso do processo de institucionalização, ou mais precisamente, da excessiva dependência institucional, também produzida no contexto dos novos serviços de 
saúde mental. Evitar que os novos serviços reproduzam a lógica da exclusão social e reforcem as rupturas existenciais ocasionadas pelos transtornos mentais é um grande desafio a ser enfrentado pelos novos profissionais do campo e nosso estudo aponta para caminhos de enfrentamento desse desafio.

A necessidade de reconstruir os vínculos do individuo com o mundo, sua identidade complexa, seu poder de sujeito social para emprestar sentido à sua existência aponta também para a importância das ações intersetoriais. Considerando que a promoção da saúde não deve ser vista como questão restrita ao campo biomédico, mas que implica em ações que conferem existência social, econômica, jurídica, enfim, a todos os campos que ligam o sujeito ao mundo, a ação de saúde será mais eficaz quanto maior estiver contextualizada e enraizada na realidade sócio-economicapolitica-cultural de um grupo e em seu universo simbólico (COELHO; ALMEIDA FILHO, 2005).

MÂNGIA, E. F.; YASUTAKI, P. M. Therapeutic itinerary and new services of mental health. Rev. Ter. Ocup. Univ. São Paulo, v.19, n. 1, p. 61-71, jan./abr. 2008.

\begin{abstract}
Studies about therapeutic itineraries can bring important contributions to the planning of mental health actions, allowing better answers to the new care scenario. In this perspective, we present some results of the research "Therapeutic itinerary of users of NAPS II in Santo André city", developed in 2006, whose main objective was to know the users' therapeutic itinerary; as secondary objectives it had: to understand the way on which the disease incorporates itself on the person quotidian and on its social network; to identify the agencies of support accessed and the participation of mental health services and, finally, to recognize the aspects that contribute to the treatment process. The investigative research was compound of documentary analyses and bibliographic research; elaboration of field diary about the follow up of service's routine activities and users, and realization of interviews. The results evinced that the individuals find different ways to deal with the mental disease and that their actions are results of quotidian negotiations among the affected individual and the people of his/her social network. Thence the importance of synergy between the health services actions and those chosen by the sick individuals in the context of their social familiar networks.
\end{abstract}

KEY WORDS: Intersectorial action. Community mental health services/utilization. Activities of daily living. Interview. Community mental health centers/utilization. Mental health services/utilization.

\title{
REFERÊNCIAS
}

ALVES, P. C. B. Experiência da enfermidade. Considerações teóricas. Cad. Saúde Pública, Rio de Janeiro, v. 9, n. 3, p. 263$271,1993$.

ALVES, P. C. B.; SOUZA, I. M. A .S. Escolha e avaliação de tratamento para problemas de saúde: considerações sobre o itinerário terapêutico. In: RABELO, M. C. M.; ALVES, P. C. B.; SOUZA, I. M. A. Experiência de doença e narrativa. Rio de Janeiro: Fiocruz, 1999. p. 125-138.

AMARANTE, P. D. C. (Coord.) Loucos pela vida: a trajetória da reforma psiquiátrica no Brasil. Rio de Janeiro: Fiocruz, 1998.

BRASIL, Ministério da Saúde, SAS. Saúde mental no SUS: os centros de atenção psicossocial. Brasília: Ministério da Saúde, 2004.

COELHO, M. T. A.; ALMEIDA FILHO, N. Concepções populares de normalidade e saúde mental no litoral norte da Bahia, Brasil. Cad. Saúde Pública, Rio de Janeiro, v. 21, n. 6, 2005.

COHN, A.; NUNES, E.; JACOBI, P. R.; KARSCH, U. S. As heranças da saúde: da política da desigualdade à proposta de equidade. In: A saúde como direito e como serviço. São Paulo: Cortez, 1991. p. 13-28.

DESLANDES, S. F. CRUZ NETO, R.; GOMES, R.; MINAYO, M. C. S. (Org.). Pesquisa social: teoria, método e criatividade. Petrópolis: Vozes, 1994.

KINOSHITA, R. T. Contratualidade e reabilitação psicossocial. In: PITTA, A. (Org.) Reabilitação psicossocial no Brasil. São Paulo: Hucitec, 2001.

MANGIA, E. F.; NICACIO, F. Terapia ocupacional em saúde mental: tendências principais e desafios contemporâneos. In: 
MÂNGIA, E. F.; YASUTAKI, P. M. Itinerários terapêuticos. Rev. Ter. Ocup. Univ. São Paulo, v.19, n. 1, p. 61-71, jan./abr. 2008.

De Carlo, M. M. R. P.; Bartalotti, C. C. Terapia ocupacional no Brasil: fundamentos e perspectivas. São Paulo: Ed. Plexus, 2001. p.63-80

MINAYO, M. C. S. O desafio do conhecimento. Pesquisa qualitativa em saúde. São Paulo: Hucitec-ABRASCO, 1993.

NICÁCIO, M.F. Utopia da realidade: contribuições da desinstitucionalização para a invenção de serviços de saúde mental. Campinas, 2003. Tese (Doutorado) - Universidade Estadual de Campinas.

ORGANIZAÇÃO MUNDIAL DE SAÚDE - OMS. Relatório sobre saúde no mundo - saúde mental: nova Concepção, nova esperança. Gráfica Brasil, Organização Mundial da Saúde, 2001.

RABElo, M. C. M.; AlveS, P. C. B.; SOUZA, I. M. A. Experiência de doença e narrativa. Rio de Janeiro: Fiocruz, 1999.
RABELO, M. C. M. A experiência de indivíduos com problema mental: entendendo projetos e a sua realização. In: RABELO, M. C. M.; ALVES, P. C. B.; SOUZA, I .M. A. Experiência de doença e narrativa. Rio de Janeiro: Fiocruz, 1999. p. 205-227.

ROTELLI,F.;LEONARDIS, O.; MAURI,D. Desinstitucionalização de uma outra via. A reforma psiquiátrica italiana no contexto da Europa Ocidental e dos "Paises avançados". In: ROTELLI, F.; LEONARDIS, O.; MAURI, D.; RISIO, C. Desinstitucionalização. São Paulo: Hucitec, 1990.

SARACENO, B. Libertando identidades - da reabilitação psicossocial à cidadania possível. Belo Horizonte/Rio de Janeiro: Instituto Franco Basaglia/TeCorá, 1999.

SILVA, D. G. V.; TRENTINI, M. Narrativas como técnica de pesquisa em enfermagem. Rev. Latinoamer. Enf. Ribeirão Preto, v. 10, n. 3, 2002. 